\title{
The Research on Innovation Experimental Area of E-commerce Talents Cultivation Model
}

\author{
MENG Xian Yong ${ }^{1, a}$, XIONG Yi Qi ${ }^{1, b}$, MENG Xiang Yu ${ }^{1, c^{*}}$, WANG Zheng Bo ${ }^{2, d}$ \\ ${ }^{1}$ Zhuhai College of Jilin University, Zhuhai, China \\ ${ }^{2}$ Department of Economics and Related Studies, University of York, York, UK

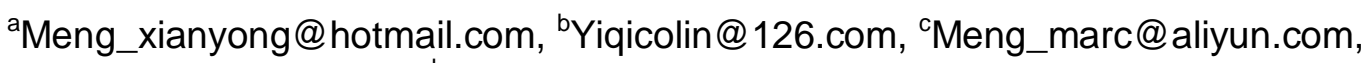 \\ 'Wang_zhengbo@hotmail.com
}

Keywords: E-commerce, Talents Cultivation Model, Innovation Experimental Area, Practical Teaching

Abstract. The innovation of E-commerce talents cultivation model is the emphasis of modern pedagogy, also is one of significant research subject about higher education research in National and Guangdong Province Medium to Long-term Development Plan and The Outline of $12^{\text {th }}$ Five-Year Development. Through carrying out "Inverted Classroom" model in E-commerce practical teaching research based on quality educational resources and "Ali ecological system", this paper realizes the innovation of E-commerce talents cultivation model. Establishing stimulating mechanism of practical teaching innovation capability, guiding mechanism of self-directed learning and cultivating mechanism of entrepreneurship ability. Simultaneously, carrying out the scientificity, feasibility, and advancement in E-commerce practical teaching clearly based on quality educational resources in Internet.

\section{Introduction}

The common requirements of Opinions on Deepening The Reform of Innovation and Entrepreneurship Education in Universities Issued by General Office of the State Council, The National Medium and Long-term Education Reform and Development Plan Outline (2010-2020), The Long-term Plan for Education Reform and Development of Guangdong Province (2010-2020), and Guangdong Province Twelfth Five-year Plan for National Economic and Social Development Program are to create E-commerce talents cultivation model innovation experimental area, let theory guide practice, practice stimulates innovation, innovation leads entrepreneurship, entrepreneurship expands employment and to improve the teaching quality of higher education [1].

From the international aspect, USA introduced entrepreneurship and practical education in higher education in 1967, the number reached to 1100 at the start of this century. Institutions of higher education carried out E-commerce practical teaching originated in USA, and Carnegie Mellon University built E-commerce College in 1998. Universities in developed countries like USA, Germany have rich experience in applied-talents practical teaching and entrepreneurship education. For example, Germany: Dual System-Four Stage Practice Teaching; Nanyang Polytechnic of Singapore: Project Teaching; and USA: Engineering Education. Universities in USA and Germany adopt flexible and varied E-commerce teaching practice activities, including holding diverse E-commerce competition, creating entrepreneurship results transfer mechanism, building students entrepreneurship park and establishing collaborative mechanism of institutions and companies, which stimulates and guides students to practice, mobilizes students active learning, collaborative learning and the enthusiasm of entrepreneurship practice. Simultaneously, the practical teaching project in USA and Germany promotes adjustment of teaching content, reform of teaching model, 
reconstruction of subject system, optimization of subject correlation, improvements of subject evaluation system, teaching quality and efficiency, internationalization of subject construction; cultivates students' practical awareness, innovation and teamwork spirit, innovative design and independent working capabilities. Some representative universities appeared, such as Harvard University and Massachusetts Institute of Technology. The practical teaching engineering projects of USA and Germany establish completed practical teaching subject system and cultivation objective, and deepen practical education. These methods give us vital revelations on our country's applied-talents cultivation model and innovation [2, 3, 4].

In recent years, 'Inverted Classroom" model, arose in Colorado, USA, has been widely used in middle and higher education. Students can learn from watching quality class records and teachers can cultivate students' independent learning abilities through centralized guidance and discussion, which can strengthen interactive leaning and solve common problems and personalized problems [5, 6].

Currently, about 300 universities and 500 colleges have established E-commerce program, and the research of E-commerce talents cultivation model innovation is still under exploring stage, the completed E-commerce talents cultivation model is unformed, especially the mature E-commerce practical teaching system, normative E-commerce practical teaching management system and scientific E-commerce practical teaching evaluation system $[7,8,9,10]$.

\section{Construction Objective}

Clarifying the Requirement Objective of E-commerce Applied Talents for Regional Economic Development. Clarifying regional development guidance. According to The Twelfth Five-year Development Planning of E-commerce of Guangdong Province, Pearl River Delta E-commerce development advantage, and demand of E-commerce talents from foreign trade companies, formulating correct E-commerce practical teaching cultivation objective and management strategy, and innovative E-commerce talents cultivation model.

Optimize "Ali Ecological System"-Related Teaching Platform. Optimize adaptive quality teaching platform of E-commerce practical education. Currently, Ali ecosystem contains platforms like Taobao, Tmall, Alibaba, Alipay, etc. Optimizing related platforms based on E-commerce practical teaching objective and developing innovative research on E-commerce talents cultivation model.

Integrating Internet Quality Education Resources Based on Ali Ecosystem. In order to innovate E-commerce talents cultivation model, combined with E-commerce practical teaching goals and Ali ecosystem platform characteristics, optimizing internet education resources such as "Mooc", "Taobao University", "Excellent Class", and "National Excellent Course", and integrate these information, forming a new internet education platform with the integration of internet theory teaching and internet practice teaching.

\section{E-commerce Practical Teaching Construction Objective Based on "Inverted Classroom" Model}

Adopt "Inverted Classroom" Model to Conduct E-commerce Practical Teaching. Setting "leading independent learning" and "strengthening interactive teaching" as objective, adopting "Inverted Classroom" model and conducting E-commerce practical teaching based on "Ali 
ecosystem" as E-commerce platform tool.

E-commerce Practical Teaching Construction Objective of "Inverted Classroom" Model. Online, students operate and manage real "Taobao" or "Tmall" online stores, comprehensively apply website design, operation and management of each part; offline, teachers analyze integratedly, guide comprehensively, discuss collectively, evaluate objectively, effectively using "Inverted Classroom" teaching model. Through "Inverted Classroom" teaching model, improve students' learning interest and teaching quality, and form guidance mechanism of self-directed learning. Through extending in-class teaching, expand students' independent learning space, cultivate entrepreneurship ability and stimulate innovation vigor.

Teaching System Construction Objective Based on "Internet Quality Education Resource". Based on internet quality education resource, formulating teaching management method and management strategy which is matched with "E-commerce practical teaching with "Inverted Classroom" model to inspire and guide students' independent learning after class. And establishing completed practical teaching management system to ensure the smooth development of practical teaching.

Construction Objective of Independent Learning Guidance Mechanism, Interaction Mechanism and Evaluation Mechanism. Formulate independent learning guidance mechanism, teaching evaluation system and teaching quality monitoring system of E-commerce practical teaching, and establish basis and criteria of measuring E-commerce practical teaching effect and quality.

Construction Objective of E-commerce Talents Cultivation Model Based on "Ali Ecosystem".

Select Platform Tools. Choose E-commerce platform tools in "Ali ecosystem" and conduct E-commerce practical teaching with "Inverted Classroom" model, formulate incentive system of practical teaching innovation capability, guidance mechanism of independent learning and cultivation mechanism of entrepreneurship ability.

Establish Improving System. Establish echelon talents cultivation model combined with E-commerce applied-talents cultivation model and "entrepreneurship and innovative"-talents cultivation model. Give those who are excellent more guidance and cultivation, to cultivate entrepreneurship and innovative-talents.

Construction Objective of Evaluation System of E-commerce Talents Cultivation Model Based on "Ali Ecosystem". Formulate basic evaluation system. Formulate basic evaluation principles based on "Ali ecosystem" practical teaching, which can evaluate basic operation technics, operation management level and website design level.

\section{Construction Scheme}

Reorganize E-commerce-Related "National and Regional" Development and Plan Outline. Reorganize E-commerce leading document include The National Medium and Long-term Education Reform and Development Plan Outline (2010-2020), The Long-term Plan for Education Reform and Development of Guangdong Province (2010-2020), Guangdong Province Twelfth Five-year Plan for National Economic and Social Development Program and The Twelfth Five-year Development Planning of E-commerce of Guangdong Province, clarify that Guangdong Province, together with Yangtze River Delta, Beijing-Tianjin-Tangshan area, have become the biggest three growth poles in our country's E-commerce development, showing characteristics of specialization, 
large-scale, and agglomeration. Blended with other industries, E-commerce fastens economic structure adjustment and industrial transformation and upgrading.

Master the Current Development Condition of E-commerce Practical Teaching. In recent years, "Inverted Classroom" model, arose in Colorado, USA, has been widely used in middle and higher education. Students can learn from watching quality class records and teachers can cultivate students' independent learning abilities through centralized guidance and discussion, which can strengthen interactive leaning and solve common problems and personalized problems. Currently, about 300 universities and 500 colleges have established E-commerce program, and the research of E-commerce talents cultivation model innovation is still under exploring stage, the completed E-commerce talents cultivation model is unformed, especially the mature E-commerce practical teaching system, normative E-commerce practical teaching management system and scientific E-commerce practical teaching evaluation system.

\section{Main Research Content of E-commerce Talents Cultivation Model Based on "Ali Ecosystem"}

Practical teaching method research. This research is based on "Ali ecosystem", conducts E-commerce practical teaching and the research of "Inverted Classroom" model around E-commerce practical teaching objective.

Practical Teaching Management Research. Formulating "Inverted Classroom" model E-commerce practical teaching management norm based on "Ali ecosystem", including practical teaching content standardization, practical teaching module standardization, practical teaching evaluation regulation standardization, innovative capability cultivation approach standardization, etc.

Practical Teaching Objective Research. According to the requirement of E-commerce talents in The Twelfth Five-year Development Planning of E-commerce of Guangdong Province, universities should cultivate high-quality E-commerce management talents, adapting regional economy and social development.

Practical Teaching Innovative Capability and Entrepreneurship Cultivation Mechanism Research. Based on "Ali ecosystem", conduct "Inverted Classroom" model E-commerce practical teaching. Through rational set up the course content and objective, establish correct cultivation mechanism of student innovation capability and entrepreneurship.

Researching the Methods of Using Quality E-commerce Platform Tools in "Ali Ecosystem". Take fully use of quality Internet practical education resource like "Taobao", "Alibaba", "Tmall", deeply investigate and analyze the characteristics of Internet education resources, and give fully play to the role in E-commerce practical teaching.

Researching the Methods of Cultivating Independent Learning Interest. Independent learning is important to improve learning quality and basic requirement of undergraduate talents cultivation. Through the research on independent learning interest cultivation mechanism of practical teaching, rationally design E-commerce practical teaching content and evaluation system based on "Inverted Classroom" model and stimulate students' initiative and creativity.

\section{Conclusions}

The research conducts E-commerce practical teaching with "Inverted Classroom" model based on Internet quality education resources in, "Ali ecosystem", and "Tencent WeChat Platform", this 
paper realizes the innovation of E-commerce talents cultivation model. Research objective is to strengthen "independent learning" and "interactive teaching" in E-commerce practical teaching. Simultaneously, clarifying the scientificity, feasibility and advancement of conducting E-commerce practical teaching based on "Ali ecosystem". Formulate E-commerce practical teaching-related management regulations, and establish guidance mechanism of independent learning, incentive system of innovative talents, and prior-cultivation mechanism of entrepreneurship.

\section{References}

[1] Abrahams, Alan, Singh, Tina. 2010. An Active, Reflective Learning Cycle for E-commerce Classes: Learning about E-commerce by Doing and Teaching. Journal of Information Systems Education 21(4): 383-390.

[2] Ann-Marie Lynam, Clare Corish, Deirdre Connolly. 2015. Development of a framework to facilitate a collaborative peer learning 2:1 model of practice placement education. Nutrition \& Dietetics 72(2): 170-175.

[3] Eric W. T. Ngai. 2004. Teaching a learning of e-commerce at the Hong Kong Polytechnic University: from business education prospective. Journal of Electronic Commerce in Organizations 2(2): 21-32.

[4] E. W. T. Ngai, S. S. Lam, J. K. L. Poon. 2013. Successful implementation of a computer-supported collaborative learning system in teaching e-commerce. International Journal of Information and Communication Technology Education 9(4): 1-20.

[5] Duan Chun Mei, Lu Hong Qian. 2014. "Teaching Content Design of Information Management for University Student of E-commerce Major". 2014 3rd International Conference on Science and Social Research.vol. 4: 245-250.

[6]Bai Dong Rui. 2011. "Campus E-commerce Entrepreneurial Mode Analysis". 2011 International Conference on Management Science and Intelligent Control (ICMSIC 2011) vol. 4:46-50.

[7] Chen Xiao Ming. 2011. "Thoughts on Improving the Effect of E-commerce Experiment Teaching". Conference on Creative Education (CCE2011), vol. 5: 230-234.

[8]Wang Wei Wei, Nan Yang, Qi Jing Jia. 2012. "A research on Based on the Skills Competition of the Electronic Commerce Professional Students' Practice Ability Training”. 2012 International Conference on Education Reform and Management Innovation (ERMI 2012). vol. 3: 132-135.

[9] Marjan Laal, Zhina Khattami-Kermanshahi, Mozhgan Laal. 2014. Teaching and Education; Collaborative Style. Procedia-Social and Behavioral Sciences 116: 4057-4061.

[10] Sanja Mohorovičić, Edvard Tijan, Dragan Čišić. 2010. Using web content management systems in university e-commerce courses. International Journal of Emerging Technologies in Learning 5(2): 38 . 